\title{
A systematic review of barriers to optimal outpatient specialist services for individuals with prevalent chronic diseases: what are the unique and common barriers experienced by patients in high income countries?
}

Elizabeth A. Fradgley*, Christine L. Paul and Jamie Bryant

\begin{abstract}
Health utilization and need assessment data suggest there is considerable variation in access to outpatient specialist care. However, it is unclear if the types of barriers experienced are specific to chronic disease groups or experienced universally. This systematic review provides a detailed summary of common and unique barriers experienced by chronic disease groups when accessing and receiving care, and a synthesized list of possible health service initiatives to improve equitable delivery of optimal care in high-income countries. Quantitative articles describing barriers to specialist outpatient services were retrieved from CINAHL, MEDLINE, Embase, and PyscINFO. To be eligible for review, studies: were published from 2002 to May 2014; included samples with cancer, diabetes mellitus, osteoporosis, arthritis, ischaemic heart disease, stroke, asthma, chronic pulmonary disorder (COPD) or depression; and, were conducted in high-income countries. Using a previously validated model of access (Penchansky and Thomas' model of fit), barriers were grouped according to five overarching domains and defined in more detail using 33 medical subject headings. Results from reviewed articles, including the scope and frequency of reported barriers, are conceptualized using thematic analysis and framed as possible health service initiatives. A total of 3181 unique records were screened for eligibility, of which 74 studies were included in final analysis. The largest proportion of studies reported acceptability barriers (75.7 \%), of which demographic disparities (44.6\%) were reported across all diseases. Other frequently reported barriers included inadequate need assessment (25.7\%), information provision (32.4 $\%)$, or health communication (20\%). Unique barriers were identified for oncology, mental health, and COPD samples. Based on the scope, frequency and measurement of reported barriers, eight key themes with associated implications for health services are presented. Examples include: common accommodation and accessibility barriers caused on service organization or physical structure, such as parking and appointment scheduling; common barriers created by poor coordination of care within the healthcare team; and unique barriers resulting from inadequate need assessment and referral practices. Consideration of barriers, across and within chronic diseases, suggests a number of specific initiatives are likely to improve the delivery of patient-centered care and increase equity in access to high-quality health services.
\end{abstract}

Keywords: Health services, Outpatient, Cancer, Depression, Diabetes mellitus, Heart diseases, Joint diseases, Stroke, Systematic review, Accessibility

\footnotetext{
* Correspondence: elizabeth.fradgley@newcastle.edu.au

Priority Research Centre for Health Behaviour and Hunter Medical Research Institute, School of Medicine and Public Health, University of Newcastle, Callaghan, NSW 2305, Australia
} 


\section{Introduction}

In the last decade, chronic diseases such as cancer, heart disease and diabetes have become the leading cause of death worldwide and are associated with $59 \%$ of deaths and $46 \%$ of the global disease burden [1]. Chronic diseases are characterised by multiple causality, genetic and lifestyle risk factors, long latency periods, and prolonged periods of illness with some level of functional impairment or disability [2]. Individuals diagnosed with a chronic disease often suffer from reduced quality of life and report poor physical functioning and emotional wellbeing [3].

Individuals with chronic diseases are frequent users of complex and costly healthcare services [4]. Chronic disease care usually requires comprehensive and personalised services involving multi-disciplinary teams. This care is often delivered at outpatient clinics, which are defined as services providing diagnostic or therapeutic care not requiring an overnight stay in a medical institution [5]. Currently, non-emergency outpatient services for chronic diseases account for a large proportion of health expenditures within high-income countries [6]. In 2011, the Organization for Economic Co-operation and Development (OECD) estimated high income countries allocate, on average, approximately $33 \%$ of their total healthcare budgets to outpatient services [6]. However, several countries dedicate an even larger proportion to these services including a variety of private and publicbased systems.

With the associated high healthcare expenditure and disease burden, effective management of chronic diseases have been targeted in policy and research initiatives. Within high-income countries, emphasis has been placed on improving the efficiency and ability of health systems to respond to chronic disease patients' evolving healthcare needs in an equitable manner. Several performance indicators relating to chronic care are incorporated into quality frameworks proposed by organizations such as the Institute of Medicine [7], the Australian National Health Performance Committee [8], the United Kingdom's National Institute of Health [9], and the World Health Organization [10]. Suggested performance domains focus on equity, effectiveness, safety, responsiveness, continuity of care, efficiency and accessibility.
Beyond these domains, patient-centered care is also considered to be essential to high quality healthcare and requires patients' preferences and values to be considered in healthcare provision [11].

Accessibility is defined as the ability to receive timely resources to manage personal healthcare needs in order to achieve the best possible outcomes [12]. Several theoretical frameworks have been proposed in order to differentiate and operationalize the factors that can act as potential barriers to receiving care [13]. Roy Penchansky and William Thomas suggested a model of fit where access is conceptualized as the degree of fit between patient need and the service's ability to respond to and meet those needs [14]. Poor 'fit' will result in an access barrier. Five distinct forms of barriers have been proposed and validated within this model (Table 1). Metrics used to describe these potential barriers to service access have included: 1) equitable patterns of service utilization according to demographic, clinical, or health insurance characteristics; 2) having a usual source of care; 3) patient need assessment, for example levels of unmet medical, supportive care, or prescription needs; and 4) patient satisfaction surveys [12, 15-17].

There is considerable inequity in access to high quality outpatient services. Health service utilization data has consistently demonstrated an association between patient characteristics and access barriers for individuals with chronic diseases. For example, ethnic minorities within the United States have been found to be significantly less likely to access outpatient services for asthma, hypertension, diabetes mellitus or congestive heart failure as compared to Caucasians [18]. This trend has also been identified in access to oncology services [19].

The proportion of unmet needs reported by patients is significantly higher for those with chronic diseases and increases with comorbidities [20]. Results from the Canadian Community Health Survey and national hospitalisation data report that unmet needs in samples of people with chronic diseases remain disproportionally high even after controlling for socio-demographic characteristics [20]. Research also suggests individuals with chronic diseases (lasting at least 6 months with restrictions in activities of daily living) were three times more

Table 1 Definition of barriers within the model of fit

\begin{tabular}{ll}
\hline Form of barrier & Definitions [107] \\
\hline Availability & The relationship between the volume or type of existing services and patient volume or type of needs. \\
$\begin{array}{ll}\text { Accessibility } & \text { The relationship between the location of health services and the location of the patients. } \\
\text { Accommodation } & \text { The relationship between the manner in which the supply resources are organized to accept patients and the patients' ability to } \\
\text { accommodate to these factors. } & \text { The relationship between prices of services and the patients' ability and willingness to pay for these services. } \\
\text { Affordability } & \begin{array}{l}\text { The relationship between patients' attitudes to personal and practice characteristics of existing providers and alternatively, provider } \\
\text { perceptions of patients' characteristics. }\end{array}\end{array}$
\end{tabular}


likely to report an unmet need than individuals without a chronic disease [4]. Overall, health service utilization and need assessment survey data suggest individuals with chronic diseases struggle to access required health services; while these health services struggle to meet patients' ongoing needs.

Health service planning and policy would benefit from detailed information on the scope of common and unique (i.e., disease-specific) barriers to optimal care. Currently, there is a lack of research comparing the barriers to care experienced across groups with chronic diseases [21]. While there are some trends in the types of barriers experienced by these groups, there has been no overarching review to distinguish experiences or concerns which are common across chronic disease groups compared to those which are unique to particular groups or diseases. Understanding the unique barriers to care experienced by particular groups may help to guide health service research to develop quality initiatives to target specific accessibility issue; conversely, those barriers that are common across groups should be prioritised and managed on a system-level.

This systematic literature review will examine the common and unique barriers experienced by nine chronic disease groups when accessing specialist outpatient care. For the purposes of this review, the definition of barrier proposed within the model of fit will be used - any factor which impedes or reduces the availability, accessibility, affordability, accommodation or amenability of outpatient care [14]. Additional factors that influence patient unmet needs, utilization patterns, and satisfaction that are not adequately captured by the model of fit will also be recorded. This includes patient-centered care domains, such as support for self-management or care coordination within multidisciplinary teams, that have recently become corner-stones of healthcare quality initiatives $[11,22]$. The results will be highly applicable to a range of chronic disease health services and will be the preliminary step to understanding how limited access and unmet needs can be appropriately addressed by quality improvement initiatives within specialized outpatient settings.

\section{Objectives}

This systematic review of quantitative studies was conducted to describe:

1. The scope and frequency of barriers reported by chronic disease patients when accessing outpatient specialist services;

2. The common and unique barriers that are reported across or within chronic diseases.

Beyond providing a quantitative description of the scope, frequency, and commonality of barriers experienced when accessing services, recurrent themes within the reviewed studies were summarized and framed within the context of health service interventions. This synthesis of study results provides a preliminary understanding of those approaches capable of improving the equitable delivery of chronic disease outpatient care within high-income countries.

\section{Review \\ Methods}

A systematic literature review of quantitative studies was conducted according to The Preferred Reporting Items for Systematic Reviews and Meta-Analyses (PRISMA) statement [23].

\section{Search strategy}

Search terms were generated iteratively by the research team and reviewed by an experienced medical librarian. Search terms used in various combinations included: chronic disease; neoplasm; outpatient or ambulatory services. The following search limits were applied: English language; all adults defined as over the age of eighteen years; and publication date between 2002 and 2014. This year range was applied to capture articles published in response to several seminal articles released in 2001 that proposed accessibility as a quality indicator. This includes the Institute of Medicine's Crossing the Quality Chasm [7]. An example of the electronic search strategy is available in the Supplementary Material (Additional file 1).

\section{Information sources}

The search was conducted in: the Cumulative Index to Nursing and Allied Health Literature (CINAHL); Embase; MEDLINE; and PsychINFO. The final search was completed May 2014.

\section{Eligibility criteria}

Quantitative or mixed methods studies which report barriers to receiving optimal specialist outpatient care were eligible for review. Six inclusion and eight exclusion criteria were applied to retrieved articles (Table 2). To ensure articles were relevant within high-income countries, only research conducted in 31 high-income Organization for Economic Co-operation and Development (OECD) countries were eligible for review [24]. A total of nine prevalent chronic diseases were included: Type 2 diabetes, arthritis, osteoporosis, ischaemic heart disease (coronary heart disease), stroke, depression, asthma, non-melanoma cancers, and chronic obstructive pulmonary disorders. These diseases were selected as they have been proposed as health priority areas within Australia [25], the Pan-Americas [26], Europe [27], and are included in major WHO reports relating to chronic diseases [28].

Paediatric research was excluded. Research involving childhood cancer survivors was included if the majority 
Table 2 Eligibility criteria for all retrieved articles

\begin{tabular}{|c|c|}
\hline Inclusion criteria & Exclusion criteria \\
\hline 1. Quantitative or mixed methods study design & $\begin{array}{l}\text { 1. Qualitative study design, editorial letters, opinion articles or teaching } \\
\text { documents }\end{array}$ \\
\hline $\begin{array}{l}\text { 2. Adult patient, health service professionals or support persons are } \\
\text { sampled }\end{array}$ & 2. Paediatric samples (less than 18 years of age) \\
\hline \multirow[t]{3}{*}{ 3. Study setting is an outpatient specialist service } & $\begin{array}{l}\text { 3a. Participants are recruited from outpatient settings, but barriers to other } \\
\text { care settings are assessed }\end{array}$ \\
\hline & 3b. Palliative, emergency or in-patient services only \\
\hline & 3c. Non specialist services only (such as primary care practices) \\
\hline $\begin{array}{l}\text { 4. Study must clearly specify one or more of diseases of interest are } \\
\text { included in the study sample. }\end{array}$ & 4. Acute or other chronic diseases not listed as diseases of interest \\
\hline 5. A barrier to optimal outpatient care is measured & $\begin{array}{l}\text { 5. No barrier is measured (eg. treatment efficacy, diagnostic protocol, } \\
\text { symptom or disease prevalence) }\end{array}$ \\
\hline 6. High income OECD countries ${ }^{a}$ & 6. All middle or low income non-OECD countries \\
\hline 7. Full text articles published in English & $\begin{array}{l}\text { 7. Conference proceedings, unavailable full text articles or article not } \\
\text { published in English }\end{array}$ \\
\hline
\end{tabular}

${ }^{\mathrm{a}}$ Defined by the World Bank based on 2011 Gross National Income per capita [24]

$(>50 \%)$ of participants were eighteen years of age or older. Several studies explored barriers across specialist, primary care, and inpatient services - these studies were only included if the majority of participants ( $>50 \%)$ accessed outpatient services or a sub-group analysis was performed. Eligibility criteria were independently pilot tested by two members of the research team with a random sample of titles and abstracts (10\%).

\section{Study selection process}

Using the eligibility criteria, a research team member reviewed all titles and abstracts. A random $10 \%$ of these were reviewed by an independent secondary reviewer. A Cohen's kappa value was recorded to assess inter-rater reliability. Discrepancies between the two reviewers were discussed, and if unresolved, a third reviewer was included to reach consensus. The study selection process was facilitated by Synthesis, a literature review software package [29].

\section{Data collection process}

Study characteristics and data describing the barriers to receiving optimal outpatient care were extracted from full-text articles using a structured electronic form. All eligible full-text articles were coded by one reviewer, with a random $10 \%$ of articles coded by a second independent reviewer. Coded results from the two reviewers were compared to ensure the process was systematic and comprehensive.

\section{Data items}

Data items were extracted to address the following study objectives:

Objective 1: To describe the scope and frequency of barriers experienced when accessing specialist outpatient services, the following was recorded: 1) if a barrier relating to one of five domains within the model of fit - availability, accessibility, affordability, accommodation or acceptability (defined in Table 1)- was assessed; 2) the disease(s) of interest; and 3) the service(s) of interest. To describe any additional variables focusing on any barriers to optimal outpatient care that were not adequately captured within the model of fit, patient-centered care domains including information provision, self-management, need assessment, coordination of care, and medical errors were also recorded.

For each of the five domains defined in the model of fit and for additional barriers to optimal care, key terms were used to describe barriers in more detail. Where possible, Medical Subject Headings (MeSH) were chosen. For example, a general affordability barrier could be described as inadequate insurance coverage (MeSH: health insurance) or inability to pay for initial services or ongoing care (MeSH: medical fees).

Objective 2: To describe the common and unique barriers reported by chronic diseases, the number of disease groups reporting the barrier was recorded. A barrier was considered common if reported in relation to three or more diseases. Alternatively, a barrier was considered unique if reported in relation to one or two diseases. This range was selected as the high volume of oncology studies masked potential unique barriers experienced by only one other chronic disease, such as depression.

Finally, in order to frame these results within the context of health service interventions, the research team summarized emerging concepts using a thematic analysis approach [30]. To determine those concepts which were of most significance and relevance to outpatient service, raw study data were recorded and 
recurrent themes were summarized by the research team. This is considered as a data-driven thematic approach [30].

\section{Summary measures}

If reported, the proportion or odds ratio of participants indicating a barrier was recorded as raw data. Due to the heterogeneity of study designs and outcome measures, meta-analysis could not be conducted.

\section{Results and discussion Study selection}

A total of 3263 records were identified using the electronic search strategy, of which 3181 were unique records (Fig. 1). The eligibility screening process excluded 2767 abstracts. The initial kappa value reported for agreement between the two raters when reviewing the first 10 $\%$ of abstracts (selected using a statistical software random number generator) was 0.72 , indicating substantial interrater reliability [31]. After discussion, all eligibility disagreements were resolved.

A total of 414 full text articles were screened for eligibility. The initial kappa value reported for agreement between the two raters when reviewing the first $10 \%$ of full text articles (selected using a statistical software random number generator) was 1.0, indicating perfect agreement [31]. The eligibility screening process excluded 340 full text articles. The most common reasons for exclusion were not including a specialist outpatient setting (28.2\%), not measuring any barriers (38.8\%), or conference proceedings (15.3\%). One paper was excluded as the authors did not respond to a request for additional clarification on the applied study measure. A total of 74 articles met eligibility criteria and were included in the review (Fig. 1).

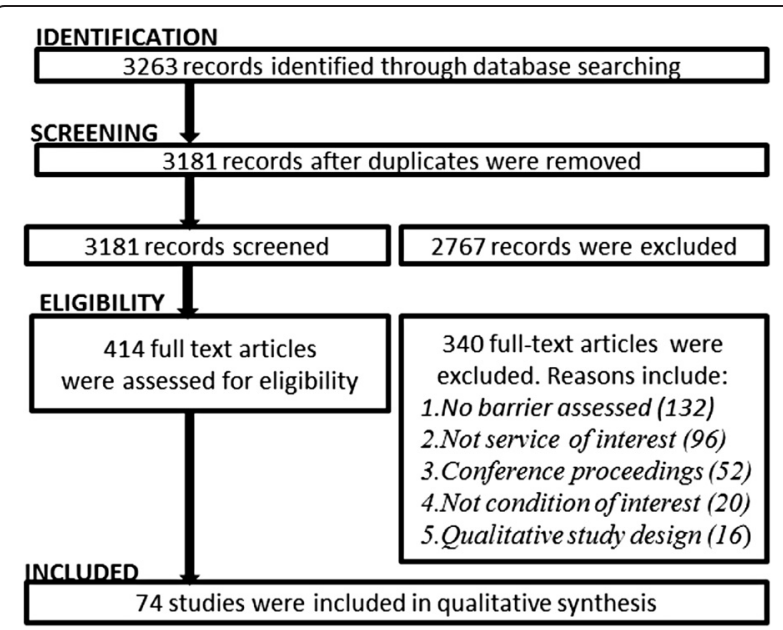

Fig. 1 Study selection and screening process

\section{Study characteristics}

The majority of studies employed a descriptive crosssectional survey design (50 of 74 studies, $67.6 \%$ ) [32$81]$ and all chronic diseases of interest were reported in at least one article. However, the volume of articles differed between chronic diseases: 59 articles $(79.7 \%)$ included oncology samples [19, 32-40, 42-47, 50-55, 57-63, 65-72, 74, 76-96]; 12 articles (16.2\%) included depression [32, 33, 41, 62, 64, 75, 83, 93, 97-100]; 10 articles (13.5 \%) included diabetes [18, 32, 33, 64, 74, $75,83,101-103$ ]; 10 articles (13.5 \%) included ischaemic heart disease $[18,32,33,48,56,64,74,75,83$, 102]; 7 articles (9.5 \%) included COPD [32, 33, 49, 56, $74,75,102] ; 7$ articles (9.5 \%) included asthma [18, 32, $33,64,74,75,83] ; 6$ articles $(8.1 \%)$ included arthritis [32, 33, 73-75, 83]; and 3 articles (4.1\%) included osteoporosis [73-75]. A total of 12 studies (16.2 \%) included more than one disease of interest $[18,32,33,56$, $62,64,73-75,83,93,102]$. As such, excepting oncology, diseases of interest were predominately analysed as part of a cluster.

\section{Results of individual studies}

Objective 1: The scope and frequency of accessibility barriers On average, studies examined $1.67(\mathrm{SD}=1.11)$ of the five overarching barriers to specialist care outlined in the model of fit. No study examined all five overarching barriers. The scope and frequency of barriers reported for each domain is provided in Table 3.

A total of 56 studies measured an acceptability barrier $(75.7 \%)$ and this was the most common barrier assessed. Within this domain, a total of 33 studies (44.6\%) reported patient demographics as a potential acceptability barrier to outpatient specialist care. It is important to note that demographic characteristics also served as moderator variables for other barriers. For example, male gender and lower income were associated with decreasing continuity of specialist care [101]. A total of 38 studies (51.4\%) examined other barriers (i.e., outside the model of fit) to optimal specialist care, including undetected or untreated physical or emotional issues and significant levels of unmet needs.

\section{Objective 2: Common and unique barriers experienced by} patients with chronic diseases

Twenty three specific barriers were considered to be common across chronic diseases (Table 4) and ten were considered unique (Table 5). It is important to consider the number of studies reporting each of these barriers, particularly as the volume of articles differed between oncology and other chronic diseases. For example, sixteen oncologyspecific studies reported communication with health professionals as an acceptability barrier [34, 36, 37, 40, 42, 51, 
Table 3 Percentage of reviewed studies reporting each overarching and specific barrier to specialist outpatient care $(n=74)$

\begin{tabular}{|c|c|c|}
\hline Barrier to outpatient services & Percentage of studies ( $n$ ) & References \\
\hline Availability & $28.4(21)$ & \multirow[t]{6}{*}[32-34,37,39,40,52,55,58,61-63,67,68,71,76,77,79,89,93,95]{} \\
\hline Delays & $6.8(5)$ & \\
\hline Provider availability & $8.1(6)$ & \\
\hline Consultation time & $6.8(5)$ & \\
\hline Service availability & $6.8(5)$ & \\
\hline Referral & $11.0(8)$ & \\
\hline Accessibility & $14.9(11)$ & \multirow[t]{5}{*}[33,36,37,54,60,61,65,67,69,77,79]{} \\
\hline Environment, parking & $9.4(7)$ & \\
\hline Transport & $5.4(4)$ & \\
\hline Professional practice location & $2.7(2)$ & \\
\hline Lodgings & $1.4(1)$ & \\
\hline Affordability & $23.0(17)$ & \multirow[t]{6}{*}[19,32,36,39,47,49,55,57,61,69,74,75,83,87,96,98,103]{} \\
\hline Medical fees & $5.4(4)$ & \\
\hline Health insurance & $10.8(8)$ & \\
\hline Prescription fees & $4.1(3)$ & \\
\hline Cost of illness, economic & $4.1(3)$ & \\
\hline Affordability, general & $5.4(4)$ & \\
\hline Accommodation & $25.7(19)$ & \multirow[t]{7}{*}[32-34,37,52,59,60,63,64,70,71,75,77,80,87,89,90,92,101]{} \\
\hline Appointments and scheduling & $4.1(3)$ & \\
\hline Wait times & $9.5(7)$ & \\
\hline Out of hours care & $6.8(5)$ & \\
\hline Continuity of care & $10.8(8)$ & \\
\hline Provider contact & $4.1(3)$ & \\
\hline Accommodation, general & $2.7(2)$ & \\
\hline Acceptability & $75.7(56)$ & \multirow{8}{*}{$\begin{array}{l}{[18,19,32,34,36-40,42,45,47,50-52,54-57,59-65,67,68,70,71,} \\
73-80,84-94,96,97,99-103]\end{array}$} \\
\hline Healthcare disparity, demographic & $44.6(33)$ & \\
\hline Decisional involvement & $16.2(12)$ & \\
\hline Health communication & $27.0(20)$ & \\
\hline Professional-patient relations (interpersonal skills) & $17.6(13)$ & \\
\hline Choice of professional & $2.7(2)$ & \\
\hline Clinical competence (technical skills) & $8.2(6)$ & \\
\hline Patient motivation or willingness to accept care & $5.4(4)$ & \\
\hline Other barriers to optimal outpatient services & $51.4(38)$ & \multirow{7}{*}{$\begin{array}{l}{[32,33,35-37,41,43-48,50,52,53,55,56,58-61,63,65-67,69} \\
71-73,76,77,79-82,84,89,93]\end{array}$} \\
\hline Need assessment, undetected or untreated issues & $25.7(19)$ & \\
\hline Service amenities & $12.2(9)$ & \\
\hline Consumer information & $32.4(24)$ & \\
\hline Patient care team, coordination and medical record & $9.5(7)$ & \\
\hline Self care & $5.4(4)$ & \\
\hline Medical errors & $2.7(2)$ & \\
\hline
\end{tabular}

$59,60,71,76,77,80,86,91,92,94]$, whereas only four studies reported a similar barrier within any of the other eight diseases of interest $[32,56,64,93]$.
Common barriers

Within each domain, several barriers were common across chronic diseases (Table 4). As the most 
Table 4 Common barriers to specialist outpatient care by chronic condition and number of corresponding studies

\begin{tabular}{|c|c|c|c|c|c|c|c|c|c|c|c|c|}
\hline \multirow[t]{2}{*}{ Barrier } & \multicolumn{10}{|c|}{ Reported in relation to: } & \multicolumn{2}{|l|}{ Number of studies } \\
\hline & CAN & AST & DEP & DIA & ISC & $\mathrm{COP}$ & ART & OST & STR & Total \# & Oncology only $(n=53)$ & Other disease $(n=21)$ \\
\hline \multicolumn{13}{|l|}{ Acceptability } \\
\hline Decisional involvement & $\checkmark$ & $\checkmark$ & $\checkmark$ & $\checkmark$ & $\checkmark$ & $\checkmark$ & $\checkmark$ & & & 7 & 9 & 3 \\
\hline $\begin{array}{l}\text { Healthcare disparity by } \\
\text { patient demographics }\end{array}$ & $\checkmark$ & $\checkmark$ & $\checkmark$ & $\checkmark$ & $\checkmark$ & $\checkmark$ & $\checkmark$ & $\checkmark$ & $\checkmark$ & 9 & 22 & 11 \\
\hline Health communication & $\checkmark$ & $\checkmark$ & $\checkmark$ & $\checkmark$ & $\checkmark$ & $\checkmark$ & $\checkmark$ & & & 7 & 16 & 4 \\
\hline Professional-patient relations & $\checkmark$ & $\checkmark$ & $\checkmark$ & $\checkmark$ & $\checkmark$ & & & & & 5 & 12 & 1 \\
\hline \multicolumn{13}{|l|}{ Accessibility } \\
\hline Parking & $\checkmark$ & $\checkmark$ & $\checkmark$ & $\checkmark$ & $\checkmark$ & $\checkmark$ & $\checkmark$ & & & 7 & 6 & 1 \\
\hline Professional practice location & $\checkmark$ & $\checkmark$ & $\checkmark$ & $\checkmark$ & $\checkmark$ & $\checkmark$ & $\checkmark$ & & & 7 & 2 & 1 \\
\hline Transport & $\checkmark$ & $\checkmark$ & $\checkmark$ & $\checkmark$ & $\checkmark$ & $\checkmark$ & $\checkmark$ & & & 7 & 3 & 1 \\
\hline \multicolumn{13}{|l|}{ Accommodation } \\
\hline Appointments and scheduling & $\checkmark$ & $\checkmark$ & $\checkmark$ & $\checkmark$ & $\checkmark$ & $\checkmark$ & $\checkmark$ & & & 7 & 2 & 1 \\
\hline Continuity of care & $\checkmark$ & $\checkmark$ & $\checkmark$ & $\checkmark$ & $\checkmark$ & $\checkmark$ & $\checkmark$ & $\checkmark$ & & 8 & 4 & 3 \\
\hline Out of hours care & $\checkmark$ & $\checkmark$ & $\checkmark$ & $\checkmark$ & $\checkmark$ & $\checkmark$ & $\checkmark$ & & & 7 & 2 & 3 \\
\hline Provider contact & $\checkmark$ & $\checkmark$ & $\checkmark$ & $\checkmark$ & $\checkmark$ & $\checkmark$ & $\checkmark$ & & & 7 & 1 & 2 \\
\hline Wait times & $\checkmark$ & $\checkmark$ & $\checkmark$ & $\checkmark$ & $\checkmark$ & $\checkmark$ & $\checkmark$ & & & 7 & 6 & 1 \\
\hline \multicolumn{13}{|l|}{ Affordability } \\
\hline General affordability & $\checkmark$ & $\checkmark$ & $\checkmark$ & $\checkmark$ & $\checkmark$ & $\checkmark$ & $\checkmark$ & $\checkmark$ & & 8 & 2 & 2 \\
\hline Health insurance & $\checkmark$ & $\checkmark$ & $\checkmark$ & $\checkmark$ & $\checkmark$ & $\checkmark$ & $\checkmark$ & $\checkmark$ & & 8 & 5 & 3 \\
\hline Medical fees & $\checkmark$ & $\checkmark$ & $\checkmark$ & $\checkmark$ & $\checkmark$ & $\checkmark$ & $\checkmark$ & & & 7 & 2 & 2 \\
\hline Prescription fees & $\checkmark$ & $\checkmark$ & $\checkmark$ & $\checkmark$ & $\checkmark$ & $\checkmark$ & $\checkmark$ & & & 7 & 0 & 3 \\
\hline \multicolumn{13}{|l|}{ Availability } \\
\hline Delays & $\checkmark$ & $\checkmark$ & $\checkmark$ & $\checkmark$ & $\checkmark$ & $\checkmark$ & $\checkmark$ & & & 7 & 3 & 2 \\
\hline Service availability & $\checkmark$ & $\checkmark$ & $\checkmark$ & $\checkmark$ & $\checkmark$ & $\checkmark$ & $\checkmark$ & & & 7 & 4 & 1 \\
\hline \multicolumn{13}{|l|}{ Optimal care } \\
\hline Consumer information & $\checkmark$ & $\checkmark$ & $\checkmark$ & $\checkmark$ & $\checkmark$ & $\checkmark$ & $\checkmark$ & & & 7 & 21 & 3 \\
\hline Medical errors & $\checkmark$ & $\checkmark$ & $\checkmark$ & $\checkmark$ & $\checkmark$ & $\checkmark$ & $\checkmark$ & & & 7 & 1 & 1 \\
\hline Patient care team, coordination & $\checkmark$ & $\checkmark$ & $\checkmark$ & $\checkmark$ & $\checkmark$ & $\checkmark$ & $\checkmark$ & & & 7 & 4 & 3 \\
\hline Self care & $\checkmark$ & $\checkmark$ & $\checkmark$ & $\checkmark$ & $\checkmark$ & $\checkmark$ & $\checkmark$ & & & 7 & 3 & 1 \\
\hline Service amenities & $\checkmark$ & $\checkmark$ & $\checkmark$ & $\checkmark$ & $\checkmark$ & $\checkmark$ & $\checkmark$ & & & 7 & 8 & 1 \\
\hline
\end{tabular}

CAN Cancer, AST Asthma, DEP Depression, DIA Diabetes, ISC Ischaemic heart disease, COP Chronic obstructive pulmonary disorder, ART Arthritis, OST Osteoporosis, STR Stroke

frequently described barrier to outpatient care, difference in service use, levels of need, or satisfaction according to demographic characteristics were reported across all diseases of interest $[18,19,34,38,41,45,47,51,52,54,55$, $57,61,64,65,68,74,75,79,84,85,87-89,91,92,96,97$, 99-103]. Additional barriers resulting from sub-optimal interactions with healthcare teams or non-patient focussed health service organization were commonly reported.

Common barriers resulting from health service organization or physical structure included: waitlists and appointments delays [32, 33]; poor service availability [33, 52, 55, 58, 63]; difficulties with parking $[33,36,37,60,65,77,79]$; poor transport options [33,
$36,61,69]$; distance to the outpatient clinic [33, 54, 67]; inability to meet medical fees [32, 47, 49,61] or prescription costs $[32,49,83]$; inadequate health insurance coverage $[19,39,47,55,75,83,87,98]$; and poor service amenities $[33,37,46,60,65,71,77,79$, 89].

Common barriers resulting from sub-optimal interactions with healthcare teams included: decisional involvement [32, 40, 50, 51, 56, 59, 60, 64, 67, 92, 71, 80]; communication with health professionals [32, 34, 36, 37, $40,42,51,56,59,60,64,71,76,77,80,86,91-94]$; relations with health professionals [37, 38, 40, 42, 51, 59, 60, $64,65,71,77,80,89]$; inadequate information provision 
Table 5 Unique barriers to specialist outpatient care by chronic condition and number of corresponding studies

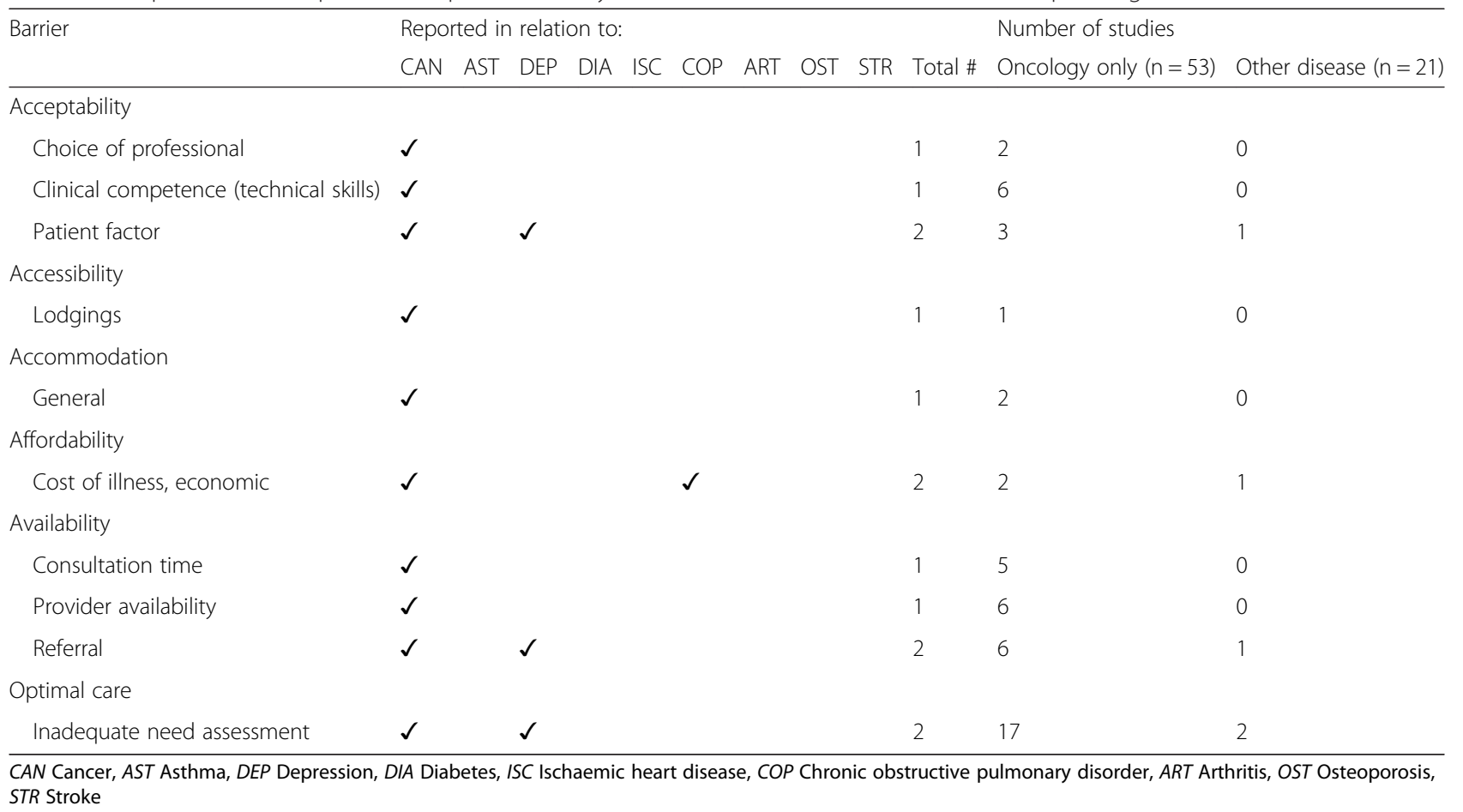

$[32,33,36,37,45-47,50,52,53,55,56,59-61,63,65$, $67,69,71,77,81,82,89]$; poor coordination of care and information within the care team $[32,33,43,48,60,77$, 80]; limited support for self-care practices [32, 59, 76, 82]; and medical errors [32, 77].

\section{Unique barriers}

Ten barriers were considered unique and were predominately reported in oncology and depression samples (Table 5). Unique barriers to oncology care included access to or information on accommodation for those who were required to travel for treatment [69]; inadequate consultation time $[34,37,40,76,79]$; poor provider availability [37, 39, 55, 89, 95, 79]; professionals' technical skills or clinical competence [37, 40, 42, 76, 79, 89]; and option to choose their healthcare professional [39, 63]. Cost of illness was reported as a barrier by both oncology and COPD patients [36, 49, 69].

Studies examining oncology, depression or the comorbid relationship between these diseases also reported: poor referral practice [52, 61, 62, 67, 71, 76, 93, 95]; inadequate need assessment $[35,41,43-45,47,50,52,53$, 59, 65-67, 72, 76, 80, 81, 84, 93]; and patient factors, such as motivation and willingness to accept care, as barriers to outpatient care $[39,62,63,76]$. For example, patients' level of perceived need was significantly associated with outpatient mental health service use [62]. Similarly, adult cancer survivors did not seek care if they felt they were in good health [63] or did not perceive the services were relevant to those in remission [39].

\section{Key themes and implications for health services}

Results from this review suggest there are a wide range of barriers experienced by chronic disease outpatients. Following thematic analysis and synthesizing the results of the 74 reviewed studies, eight key themes according to the scope, frequency and commonality of barriers were found and are summarized below. Themes 1 through 6 are based on recurrent findings across individual studies. Themes 7 and 8 are reflections on the overall state of the evidence relating to barriers to specialist outpatient care. Health service or research implications for each of these themes can be found in Table 6 and provides a set of possible approaches for improving equity to high-quality specialist services.

\section{Theme 1: Patient demographic characteristics frequently create or exacerbate barriers}

Of the reviewed articles, the most frequently reported barrier to care examined was acceptability. This was primarily due to the focus on patients' demographic characteristics as both a barrier to receiving optimal care and as a critical factor in mediating the magnitude of barriers experienced. Examples include examining disparities according to race $[18,19,91,102]$; education $[61,71]$; age $[65,71,89,92]$; gender $[51,52,65]$; presence of comorbidities, disease severity or reduced health status [89, 
Table 6 Summary of key themes and implications for health services and research

\begin{tabular}{|c|c|c|}
\hline Summarized themes & $\begin{array}{l}\text { Relation to study } \\
\text { objective }\end{array}$ & Health service or research implications \\
\hline \multirow[t]{3}{*}{ Demographic characteristics create or exacerbate barriers } & \multirow[t]{3}{*}{ Frequent barrier } & $\begin{array}{l}\text { Improve breadth of patient participation and health literacy } \\
\text { to reduce disparities }\end{array}$ \\
\hline & & $\begin{array}{l}\text { Assess the degree to which services are culturally } \\
\text { competent }\end{array}$ \\
\hline & & $\begin{array}{l}\text { Target disadvantaged groups with additional supportive } \\
\text { services }\end{array}$ \\
\hline Availability barriers exist at first point of contact & Common barrier & Provide explanations for and estimates of delays \\
\hline \multirow{6}{*}{$\begin{array}{l}\text { Service structures create accommodation and accessibility } \\
\text { barriers }\end{array}$} & \multirow[t]{6}{*}{ Common barrier } & Improve appointment scheduling systems: \\
\hline & & - record individual preferences for date and time \\
\hline & & $\begin{array}{l}\text { - coordinate all required appointments at the facility on one } \\
\text { day }\end{array}$ \\
\hline & & -convenient rescheduling process \\
\hline & & Decrease wait-times \\
\hline & & Incorporate notification system for estimated wait-times \\
\hline \multirow[t]{5}{*}{ Continuity and coordination of care poses barriers } & \multirow[t]{5}{*}{ Common barrier } & Improve content and access to medical records: \\
\hline & & -systematic data collection for accuracy and completeness \\
\hline & & ability to record additional patient concerns \\
\hline & & -notification or alerts when test results are available \\
\hline & & $\begin{array}{l}\text {-centralized progress summaries for multiple service } \\
\text { providers }\end{array}$ \\
\hline \multirow{5}{*}{$\begin{array}{l}\text { Decisional involvement and information provision impacts } \\
\text { acceptability of care }\end{array}$} & \multirow[t]{5}{*}{ Common barrier } & Provide personalized information to patients \\
\hline & & $\begin{array}{l}\text { Provide ongoing opportunities to review progress and } \\
\text { concerns }\end{array}$ \\
\hline & & Provide access to additional information sources \\
\hline & & Provide communication training for providers \\
\hline & & $\begin{array}{l}\text { Consider and discuss individual patient preferences for } \\
\text { decisional involvement }\end{array}$ \\
\hline \multirow[t]{3}{*}{$\begin{array}{l}\text { Need assessment and referral processes for cancer and/or } \\
\text { depression can be improved }\end{array}$} & \multirow[t]{3}{*}{ Unique barrier } & $\begin{array}{l}\text { Conduct systematic, comprehensive and routine screening } \\
\text { of patients' needs }\end{array}$ \\
\hline & & Refer automatically to support services \\
\hline & & Inform health professionals of additional services available \\
\hline Barriers can be described in additional detail & Scope of barrier & $\begin{array}{l}\text { Deconstruct barriers to design more targeted initiatives for } \\
\text { improving access }\end{array}$ \\
\hline \multirow[t]{2}{*}{ Evidence on barriers to non-oncology services is limited } & \multirow[t]{2}{*}{ Volume of articles } & $\begin{array}{l}\text { Barriers reported within clusters of conditions mask } \\
\text { differences across groups }\end{array}$ \\
\hline & & Conduct more studies in non-oncology patient groups \\
\hline
\end{tabular}

92, 103]; and socioeconomic groupings [74, 96, 101]. For example, using the population-based Nord-Tondelag Health Survey (HUNT-3), Vikum et al. explored the differential use of healthcare according to patients' education levels and household income [74]. The large sample $(\mathrm{n}=$ 44,755 ) included patients who self-reported suffering from one or more of 18 chronic diseases including: cancer; diabetes; respiratory illness, such as COPD and asthma; musculoskeletal disorders, such as arthritis and osteoporosis; and stroke. Overall, the need for all services was greatest for those in lower income groups and a positive significant relationship exists between both income and education levels and the use of outpatient specialist services, with the exception of males aged 20-39 years.

Socioeconomic status was a common demographic variable of interest and, as one would expect, was related to an individual's ability and willingness to pay for services. Approximately 17 articles explored a barrier resulting from the cost of healthcare $[19,32,36,39,47,49,55,57$, $61,69,74,75,83,87,96,98,103]$. These articles were conducted in a variety of healthcare systems, including those with publically-funded healthcare schemes designed to encourage universal access to services. This suggests that patients still must contend with several 
other sources of financial strain resulting from the need to access healthcare, such as lost-income or outof-pocket spending. While this review cannot describe the differences in the barriers experienced according to the funding structures of different OECD countries, results suggest that the affordability of healthcare and the disparities that result are still a source of considerable patient concern. This is supported by previous research [32].

\section{Theme 2: Common availability barriers exist at first point of contact with health services}

A range of availability barriers, such as delays to treatment, are considerable concerns for patients when first accessing services. Across chronic disease groups, barriers exist at first point of contact with a particular service and include delays to receiving care and limited provider availability. Delays to receiving care were reported across multiple chronic diseases and were frequently experienced within several high-income countries. Within Canada, Australia, New Zealand and the United Kingdom, the majority of patients who experienced recent ill health did not receive specialist care within 4 weeks [32]. Acceptable wait periods to receive treatment or surgical interventions have been established within national guidelines, mainly to optimize patient outcomes [68]. However, wait times also pose a significant concern from a patient perspective. Paul et al. report approximately $52 \%$ of Australian radiotherapy outpatients experienced some level of concern regarding delays in treatment [68]. Patients expect that care, particularly for recently-diagnosed prevalent chronic disease (e.g., diabetes), should be received in a timely manner and ideally within 14 days from receiving a referral [33].

\section{Theme 3: Health service structure and organization create common accommodation and accessibility barriers}

Synthesized results suggest patients continue to experience barriers over the course of their interaction with health services and patients' preferences are not accommodated within health service organization. These barriers include non-clinical aspects of the service's physical structure, such as difficulties with parking. For patients who must access services for treatment, such as intravenous chemotherapy, parking remains a major issue $[33,36,37,60,65,77,79]$. For example, within a study of cancer patients in the United Kingdom, parking was rated as the least met need despite being rated as a highly salient [65]. Non-clinical accommodation barriers were also experienced as a result of the service organizational structure. This was predominately reported by patients' dissatisfaction with appointment scheduling [71], appointment wait times, inability to contact the clinic or professionals [64], or limited availability of out of hours care [59].

Up to $60 \%$ of oncology outpatients reported that waiting times of more than 15 min contributed to poor experiences within health services [59] and lengthy wait times accounted for a third of all patient-reported experiences of poor care [77]. This represents a potential area of improvement as wait times are highly salient to patient experiences [70] and patients who experienced lengthy wait times were more likely to report significantly lower levels of satisfaction and perceive shorter consultation times [34]. Inadequate consultation times were also reported as a barrier to oncology outpatient care. Studies using the EORTC OUTPATSAT35 report both physician punctuality and the amount of physician time devoted to the patient were the worst performing subscales and received scores below 70 [79, 89]. Patients identified sufficient time to review all questions regarding disease and treatment and having their physician's complete attention as being very important when receiving a diagnosis [40].

\section{Theme 4: Common patient barriers are reported as a result of poor coordination of care}

In 2008, the Commonwealth Fund International Health Policy Survey of Sicker Adults reported a considerable proportion of patients believed their medical care was inefficient or wasteful (rates range from 27-46 \%) [32]. This negative perception of care may be a result of poor clinical competence of health professionals, lack of continuity of care, poor coordination of the patient care team, and medical errors.

Continuity and coordination has been associated with improved patient care and is frequently assessed according to patients' access to a usual source of care. For example, having a usual care provider was associated with improved screening and use of outpatient services for diabetic patients [101] and treatment of depression for patients with comorbid diseases [75]. Advanced lung cancer patients identified as having experienced poor continuity of care were more likely to have unmet supportive care needs across domains such as health information and psychological needs [80]. In addition to improved patient care and outcomes, studies consistently identify continuity of care as essential to patients' experiences of care. In a study of elderly patients' priorities for health service delivery, patients rated continuity as the most important aspect of care with approximately $94 \%$ indicating it was extremely important to see the same physician at every appointment [33]. Similarly, three studies of young adults found the majority of patients prefer follow-up care to be delivered by their treating physician and service $[34,52,63]$. 
In a study of patients' perceptions of outpatient care in eight Commonwealth countries, poor continuity or availability of information within the healthcare team was reported [32]. This included: non-availability of medical records or test results at time of scheduled appointment; unnecessary duplication of tests; and poor information exchange between general practitioners and specialists. Discrepancies in medical records were also reported by reviewed studies. For example, a review of oncology medical records revealed only $49 \%$ of symptoms were documented and patient-identified issues, such as difficulties with mobility or maintaining activities of daily life, were frequently omitted [43]. Similar discrepancies between patient-identified symptoms and documentation have been reported for patients with chronic heart disease [48].

\section{Theme 5: Aspects of the patient-physician relationship can negatively impact the acceptability of care}

Barriers in the patient-physician interaction arose when examining decisional involvement, communication, and information provision. Approximately $70 \%$ of oncology patients reported there was a difference between the ideal and actual physician relationships [51]. Of this, approximately $32 \%$ of patients reported poor decisional involvement and $28.5 \%$ did not feel encouraged by their physician. Across the 13 domains of the PASQOC survey, co-management and shared decision making had the second highest problem frequency (30\%) with a large proportion of oncology patients indicating they did not make the treatment decision (47\%) and were not effectively informed on the probability or management of side-effects ( $49 \%$ and $38 \%$, respectively) and changes to daily life (37\%) [59]. Furthermore, $34 \%$ did not feel as if they were treated as an expert on their body.

Across multiple diseases, considerable gaps in patientprovider communication were reported and included: patient preferences and goals for treatment are not discussed (26-50\%); patients are rarely or only sometimes encouraged to ask questions (24-38 \%); and are rarely or only sometimes told about treatment options and involved in decisions (12-31 \%) [32]. Within COPD and chronic heart failure (CHF) outpatients, only within 5.9 $\%$ of COPD group and $3.9 \%$ of CHF group did both patient and physician report discussing preferences for lifesustaining treatment [56].

Information on the impact of treatment and potential trade-offs between quality and prolongation of life is typically communicated by treating physicians. Within study results, patients identify information content as the most important aspect of a clinical appointment [40]. Patients attribute high importance to being informed on the best treatment options and being aware of all treatment options [40]. Additionally, patients would like to be aware of prognoses, treatment results and be provided with information on their personal situation [71]. Within oncology outpatients, patients identified a lack of information on changes in relationships, sexual activity, or emotions was an area of improvement [67]. Poor communication and information provision for family and close others was also reported within the review as an area of relatively lower quality $[51,71]$.

\section{Theme 6: Inadequate need assessment and referral practices are unique barriers experienced in relation to few chronic diseases}

Patients with cancer and/or depression diagnoses report unmet needs and referral processes as a barrier to optimal outpatient care. For patients diagnosed with depression and/or cancer, synthesized study results suggest that health professionals do not consistently identify psychological or physical symptoms. For example, within outpatient oncology clinics only $49 \%$ of patients with major depressive disorder (MDD) reported speaking to a health care professional about feeling depressed (albeit this study did not distinguish between a primary care provider or oncologist for this stage of screening); $36 \%$ reported receiving any subsequent treatment or a referral to a specialist mental health service; and in total authors estimated up to $85 \%$ of patients did not receive appropriate specialised treatment for MDD [93]. Slightly higher rates of treatment for moderate to severe symptoms of depression (61.9 \%) and anxiety (60.6 \%) were reported in a sample of several outpatient clinics specializing in cancer and chronic disease care, but this remained sub-optimal [62].

Referral processes was also reported by patients as a critical gap in the provision of outpatient care. Automatic referral to a social worker for financial, emotional, and organizational concerns was rated as important by young adults currently receiving or having completed oncology treatment [52]. Only one in two patients are referred to a social workers due to resource limitations [95]. Referral to and availability of services such as nutritional counselling, physical therapy, support groups and rehabilitation were also reported by cancer outpatients as highly important to optimal outpatient care [61]. Only one in two patients reported using such supportive services and patients' lack of knowledge of these services $(22.4 \%)$ or lack of physician referral (23\%) was reported as the main reasons for underuse. Referral was the strongest predictor of recent mental health treatment $(\mathrm{OR}=7.91)$ as compared to variables such as appointment frequency, perceived need, and prior use [62]. 
Theme 7: To provide more practice-ready evidence, barriers to outpatient specialist care should be described in additional detail

A total of 30 distinct barriers were reported within the reviewed papers. Consideration of the scope of these barriers using $\mathrm{MeSH}$ terms suggests that it is important to go beyond the overarching barriers such as the volume or affordability of available services. For example, affordability was explored in 17 papers and described four distinct forms of affordability barriers experienced by chronic disease outpatients: inadequate health insurance coverage; inability to meet the costs of medical services; inability to afford prescriptions; and the cost of illness, such as lost income for those who are unable to work. Each of these barriers requires a different type of solution suggesting it is important to have detail about the barrier in order to take appropriate action.

\section{Theme 8: This review found little evidence on barriers to non-oncology services}

There is a wealth of information on the barriers to outpatient oncology care, but barriers experienced by other chronic illnesses are less understood. A total of 59 articles described a barrier to oncology services. Comparatively, few studies (15 of 74) focused on other chronic illnesses and typically analysed barriers within a heterogeneous sample of diseases. However, it is important to note that this review may not have captured the barriers experienced by some chronic disease groups, such as people with osteoporosis, because of the limited focus on specialist services. It is possible that these groups are adequately managed within primary care settings and do not frequently require access to specialist care.

\section{Limitations}

It is possible that publication bias affected the results of this systematic review, whereby articles with significant results are more likely to be accepted in peer-review journals. By accessing only peer-reviewed studies it is possible study results over-estimates the barriers experienced by chronic disease outpatients. Grey literature or qualitative articles may have provided additional or alternative views of access to care. Additionally, most studies employed a cross-sectional survey design which may not have provided a longitudinal view of patients' ongoing experience with care. However, given the large number of articles reviewed with a range of patient samples, results are inclusive of several areas of care such as diagnosis, treatment decisions, and ongoing patient needs.

Barriers were classified according to Medical Subject Headings and grouped according to definitions proposed within Penchansky and Thomas' model of fit [14]. This required some subjectivity on behalf of the research team and the team generated a sixth barrier relating to dimensions of patient-centered care. While coding processes and data extraction was pilot-tested and agreement verified, several assumptions regarding these classifications were made. For example, specific barriers such as health communication and professional-patient relations are intertwined concepts necessary for a patient-centered approach to care. There are additional access frameworks, such as that proposed by Donabedian [104], and Andersen and Aday [105], which could have been applied within this review. Debate on the value of each framework is presented elsewhere [12], and research to evaluate the degree to which these models are inclusive of emerging quality of care dimensions would be valuable.

Subjective judgements were required when reviewing the results in order to generate thematic concepts. While this is an inherent limitation of an interpretive review, this allowed authors to provide a more concise summary of the recurrent barriers reported by a large volume of articles employing a range of measurement approaches in markedly different patient groups. Themes were generated according to well-established qualitative methods [106].

\section{Conclusions}

Overall, patients with prevalent chronic diseases experience thirty three specific barriers to outpatient care across six accessibility domains. This includes additional patient-centered care dimensions such as self-care, consumer information provision, and need assessment. By focusing on prevalent chronic diseases within outpatient specialist settings, this systematic review describes the scope and frequency of common and unique barriers to care and synthesizes this into a concise list of potential quality improvement initiatives.

Results from this review suggest that in order to design targeted initiatives, it is important characterize barriers in detail and to explore possible barriers in the delivery of patient-centered care. In examining the common barriers, four themes were recurrent across chronic disease groups. First, at initial contact with a health care service, individuals experience delays to first appointment or treatment and causes considerable patient concern. Second, patients report health services are not organized or sufficiently flexible to accommodate scheduling preferences, and the physical structure of the clinic limits accessibility. Third, poor continuity of care and information transfer in the healthcare team was perceived to negatively impact the quality of care received. Fourth, inadequate information provision and a lack of involvement in treatment decisions were reported by multiple chronic disease groups. Given these themes were recurrent across chronic disease groups, system-wide initiatives targeting these gaps in the quality of care are appropriate and should be prioritized. Health services 
may consider improvements in: appointment scheduling systems; content of and access to medical records across health professionals; and timely provision of personalized information with multiple opportunities to review patient concerns.

In examining the unique barriers experienced by only a few chronic disease groups, need assessment practices and referral processes were seen as sub-optimal by individuals diagnosed with cancer and/or depression. Health services may consider evaluating current screening practices to ensure need assessments are: routinely and systematically conducted; sufficiently flexible to document salient needs that may be outside the scope of physical or emotional concerns, such as psychosocial or spirituality needs; and provide instruction and a process to address a detected need, such as an automatic referral pathway. Results from this study suggest these initiatives may best targeted within oncology or mental health services.

\section{Additional file}

Additional file 1: Example of the electronic search strategy, including Medline database search terms and limits.

\section{Competing interests}

The authors declare that they have no competing interests.

\section{Authors' contributions}

All authors participated in conception of the study design. EF completed all database searches, data extraction and analysis. Both EF and JB completed abstract and title coding, and EF and CP completed full-text coding. All authors participated in reviewing raw data in order to summarize key themes. EF drafted the final manuscript with JB and CP reviewing the content for intellectual contribution and clarity. All authors read and approved the final manuscript.

\section{Acknowledgements}

Dr Jamie Bryant is supported by an Australian Research Council Post-Doctoral Industry Fellowship. A/Prof Christine Paul was supported by an HMRI Fellowship and an NHMRC Career Development Fellowship. This work was supported by a Strategic Research Partnership Grant from Cancer Council NSW to the Newcastle Cancer Control Collaborative (New-3C), and Hunter Medical Research Institute (HMRI) infrastructure funding. Authors would like to thank the University of Newcastle library services for reviewing the study design and search strategy.

Received: 16 November 2014 Accepted: 29 April 2015

Published online: 09 June 2015

\section{References}

1. Coleman K, Austin BT, Brach C, Wagner EH. Evidence on the Chronic Care Model in the new millennium. Health Aff (Millwood). 2009;28(1):75-85.

2. AlHW. Key indicators of progress for chronic disease and associated determinants: data report. Canberra: AlHW2011. Report No.: Cat. No. PHE 142.

3. Rothrock NE, Hays RD, Spritzer K, Yount SE, Riley W, Cella D. Relative to the general US population, chronic diseases are associated with poorer healthrelated quality of life as measured by the Patient-Reported Outcomes Measurement Information System (PROMIS). J Clin Epidemiol. 2010;63(11):1195-204. http://dx.doi.org/10.1016/j.jclinepi.2010.04.012.

4. McColl MA, Jarzynowska A, Shortt S. Unmet health care needs of people with disabilities: population level evidence. Disabil Soc. 2010;25(2):205-18.
5. Shi L, Singh DA. Delivering health care in America: Jones \& Bartlett Publishers. 2009

6. OECD. Health at a Glance 20132013

7. Institute of Medicine. Crossing The Quality Chasm: A New Health System for the 21st Century. Washington DC: National Academy Press; 2001.

8. National Health Performance Committee. National health performance framework report. Brisbane 2001.

9. Department of Health. National Standards, Local Action. Health and Social Care Standards and Planning Framework. London: Crown copyright; 2005.

10. World Health Organization. Innovative care for chronic conditions: building blocks for actions: global report. 2002

11. Gerteis M, Edgman-Levitan S, Daley J, Delbanco TL. Through the patient's eyes: understanding and promoting patient-centered care. San Francisco: Jossey-Bass; 1993.

12. Ricketts TC, Goldsmith $L$ J. Access in health services research: the battle of the frameworks. Nurs Outlook. 2005;53(6):274.

13. Levesque J-F, Harris MF, Russell G. Patient-centred access to health care: conceptualising access at the interface of health systems and populations. Int J Equity Health. 2013;12(1):18.

14. Penchansky R, Thomas JW. The Concept of Access: Definition and Relationship to Consumer Satisfaction. Med Care. 1981;19(2):127-40.

15. Kullgren JT, MCLaughlin CG. Beyond affordability: the impact of nonfinancial barriers on access for uninsured adults in three diverse communities. J Community Health. 2010;35(3):240-8.

16. Hoffman C, Paradise J. Health insurance and access to health care in the United States. Ann N Y Acad Sci. 2008;1136(1):149-60.

17. Kehle SM, Greer N, Rutks I, Wilt T. Interventions to improve veterans' access to care: a systematic review of the literature. J Gen Intern Med. 2011;26(2):689-96.

18. Kominski G, Morisky D, Afifi A, Kotlerman J. The effect of disease management on utilization of services by race/ethnicity: evidence from the Florida Medicaid program. Am J Manag Care. 2008;14(3):168-72.

19. Craig B, Bell B, Quinn G, Vadaparampil S. Prevalence of cancer visits by physician specialty 1997-2006. J Cancer Educ. 2010;25(4):548-55.

20. Ronksley PE, Sanmartin C, Quan H, Ravani P, Tonelli M, Manns B, et al. Association between perceived unmet health care need and risk of adverse health outcomes among patients with chronic medical conditions. Open Med. 2013:7(1):21-30.

21. Kohlmann S, Kilbert MS, Ziegler K. Schulz K-H. Supportive care needs in patients with cardiovascular disorders: Patient Educ Couns; 2013.

22. Epstein RM, Street RL. The values and value of patient-centered care. Ann Family Med. 2011;9(2):100-3.

23. Moher D, Liberati A, Tetzlaff J, Altman DG. Preferred reporting items for systematic reviews and meta-analyses: the PRISMA statement. Ann Intern Med. 2009:151(4):264-9.

24. The World Bank. Country and Lending Groups 2012. http://data.worldbank.org/ about/country-classifications/country-and-lending-groups\#Upper_middle income. Accessed 19/03/2013 2013.

25. National Health Priority Action Council. National Chronic Disease Strategy In: Australian Government Department of Health and Ageing, editor. Canberra 2006.

26. Pan American Health Organization. Regional strategy and plan of action on an integrated approach to the prevention and control of chronic diseases, Washington DC. 2007

27. Busse R. Tackling chronic disease in Europe: strategies, interventions and challenges, vol. 20. Europe: WHO Regional Office; 2010.

28. Organization WH. The World health report: 2002: Reducing the risks, promoting healthy life. 2002.

29. Yergens DRJ, Doig CJ, KSV2. Application for Enhancing Scoping and Systematic Reviews. Washington D.C.: American Medical Informatics Association Annual Symposium; 2012.

30. Dixon-Woods M, Agarwal S, Jones D, Young B, Sutton A. Synthesising qualitative and quantitative evidence: a review of possible methods. J Health Serv Res Policy. 2005;10(1):45-53B.

31. Landis JR, Koch GG. The measurement of observer agreement for categorical data. Biometrics. 1977;33(1):159-74.

32. Schoen C, Osborn R, How SKH, Doty MM, Peugh J. In chronic condition: experiences of patients with complex health care needs in eight countries 2008. Health Aff (Millwood). 2009:28(1-2):1-16.

33. Albada A, Triemstra M. Patients' priorities for ambulatory hospital care centres. A survey and discrete choice experiment among elderly and chronically ill patients of a Dutch hospital Health Expect. 2009;12(1):92-105. 
34. Absolom K, Greenfield D, Ross R, Horne B, Davies H, Glaser A, et al. Predictors of clinic satisfaction among adult survivors of childhood cancer. Eur J Cancer. 2006;42(10):1421-7.

35. Akechi T, Okuyama T, Endo C, Sagawa R, Uchida M, Nakaguchi T, et al. Anticipatory nausea among ambulatory cancer patients undergoing chemotherapy: prevalence associated factors and impact on quality of life. Cancer Sci. 2010;101(12):2596-600.

36. Alifrangis C, Koizia L, Rozario A, Rodney S, Harrington M, Somerville C, et al. The experiences of cancer patients. QJM. 2011;104(12):1075-81.

37. Arraras J, Rico M, Vila M, Chicata V, Asin G, Martinez M, et al. The EORTC cancer outpatient satisfaction with care questionnaire in ambulatory radiotherapy: EORTC OUT-PATSAT35 RT. Validation study for Spanish patients. Psychooncology. 2010;19(6):657-64.

38. Bitar R, Bezjak A, Mah K, Loblaw D, Gotowiec A, Devins G. Does tumor status influence cancer patients' satisfaction with the doctor-patient interaction? Support Care Cancer. 2004;12(1):34-40

39. Bowers D, Adhikari S, El-Khashab Y, Gargan L, Oeffinger K. Survey of long-term follow-up programs in the United States for survivors of childhood brain tumors. Pediatr Blood Cancer. 2009;53(7):1295-301.

40. Brown V, Parker P, Furber L, Thomas A. Patient preferences for the delivery of bad news - the experience of a UK Cancer Centre. Eur J Cancer Care (Engl). 2011;20(1):56-61.

41. Carter J, Frampton C, Mulder R, Luty S, Joyce P. The relationship of demographic clinical cognitive and personality variables to the discrepancy between self and clinician rated depression. J Affect Disord. 2010;124(1-2):202-6.

42. Chang K, Brodie R, Choong M, Sweeney K, Kerin M. Complementary and alternative medicine use in oncology: a questionnaire survey of patients and health care professionals. BMC Cancer. 2011;11(196):196.

43. Cheville A, Beck L, Petersen T, Marks R, Gamble G. The detection and treatment of cancer-related functional problems in an outpatient setting. Support Care Cancer. 2009;17(1):61-7

44. Cirillo M, Venturini M, Ciccarelli L, Coati F, Bortolami O, Verlato G. Clinician versus nurse symptom reporting using the National Cancer Institute Common terminology criteria for adverse events during chemotherapy: Results of a comparison based on patient's self-reported questionnaire. Ann Oncol. 2009;20(12):1929-35.

45. Cossich T, Schofield P, McLachlan S. Validation of the cancer needs questionnaire (CNQ) short-form version in an ambulatory cancer setting. Qual Life Res. 2004;13(7):1225-33.

46. Danhauer SC, Keim J, Hurt G, Vitolins M. A survey of cancer patient preferences: Which types of snacks do they prefer during treatment? : Erratum. Eur J Cancer Care (Engl). 2009;18(2):216.

47. Deshields T, Rihanek A, Potter P, Zhang Q, Kuhrik M, Kuhrik N, et al. Psychosocial aspects of caregiving: perceptions of cancer patients and family caregivers. Support Care Cancer. 2012;20(2):349-56.

48. Ekman I, Ehrenberg A. Fatigued elderly patients with chronic heart failure: do patient reports and nurse recordings correspond? Int J Nurs Terminol Classif. 2002;13(4):127-36.

49. Essue B, Kelly P, Roberts M, Leeder S, Jan S. We can't afford my chronic illness! The out-ofpocket burden associated with managing chronic obstructive pulmonary disease in western Sydney Australia. J Health Serv Res Policy. 2011;16(4):226-31.

50. Feyer $P$, Kleeberg $U$, Steingraber $M$, Gunther $W$, Behrens $M$. Frequency of side effects in outpatient cancer care and their influence on patient satisfaction-a prospective survey using the PASQOC questionnaire. Support Care Cancer. 2008;16(6):567-75.

51. Goldzweig G, Meirovitz A, Hubert A, Brenner B, Walach N, Perry S, et al. Meeting expectations of patients with cancer: relationship between patient satisfaction depression and coping. [Erratum appears in J Clin Oncol. 2010 Jun 1:28(16):2805 Note: Meirowitz Amichai [corrected to Meirovitz Amichay]]. J Clin Oncol. 2010;28(9):1560-5

52. Gupta A, Edelstein K, Albert-Green A, D'Agostino N. Assessing information and service needs of young adults with cancer at a single institution: the importance of information on cancer diagnosis, fertility preservation, diet and exercise. Support Care Cancer. 2013;21(9):2477-84.

53. Hartmuller WW, Desmond SM. Professional and patient perspectives on nutritional needs of patients with cancer. Oncol Nurs Forum. 2004;31 (5):989-96.

54. Hjorleifsdottir E, Rahm Hallberg I, Agren Bolmsjo I, Gunnarsdottir E. Icelandic cancer patients receiving chemotherapy or radiotherapy: does distance from treatment center influence distress and coping? Cancer Nurs. 2007;30(6):1-10
55. Huyghe E, Sui D, Odensky E, Schover L. Needs assessment survey to justify establishing a reproductive health clinic at a comprehensive cancer center. J Sex Med. 2009;6(1):149-63.

56. Janssen D, Spruit M, Schols J, Wouters E. A call for high-quality advance care planning in outpatients with severe COPD or chronic heart failure. Chest. 2011;139(5):1081-8.

57. Johnson R, Horne B, Feltbower R, Butler G, Glaser A. Hospital attendance patterns in long term survivors of cancer. Arch Dis Child. 2004;89(4):374-7.

58. Kinnane NA. Evaluation of a hospital-based cancer information and support centre. Support Care Cancer. 2012;20(2):287-300.

59. Kleeberg U, Feyer P, Gunther W, Behrens M. Patient satisfaction in outpatient cancer care: a prospective survey using The PASQOC questionnaire. Support Care Cancer. 2008;16(8):947-54.

60. Kleeberg U, Tews J, Ruprecht T, Hoing M, Kuhlmann A, Runge C. Patient satisfaction and quality of life in cancer outpatients: results of the PASQOC study. Support Care Cancer. 2005;13(5):303-10.

61. Kumar P, Casarett D, Corcoran A, Desai K, Li Q, Chen J, et al. Utilization of supportive and palliative care services among oncology outpatients at one academic cancer center: determinants of use and barriers to access. J Palliat Med. 2012;15(8):923-30.

62. Ledoux T, Barnett M, Garcini L, Baker J. Predictors of recent mental health service use in a medical population: implications for integrated care. J Clin Psychol Med Settings. 2009;16(4):304-10.

63. Maeda N, Horibe K, Kato K, Kojima S, Tsurusawa M. Survey of childhood cancer survivors who stopped follow-up physician visits. Pediatr Int 2010;52(5):806-12

64. Martsolf GR, Alexander JA, Shi Y, Casalino LP, Rittenhouse DR, Scanlon DP, et al. The Patient-Centered Medical Home and Patient Experience. Health Serv Res. 2012;47(6):2273-95.

65. Morrison V, Henderson B, Zinovieff F, Davies G, Cartmell R, Hall A, et al. Common important and unmet needs of cancer outpatients. Eur J Oncol Nurs. 2012;16(2):115-23.

66. Nakaguchi T, Okuyama T, Uchida M, Ito Y, Komatsu H, Wada M, et al. Oncology nurses' recognition of supportive care needs and symptoms of their patients undergoing chemotherapy. Jpn J Clin Oncol. 2013:43(4):369-76.

67. O'Brien I, Britton E, Sarfati D, Naylor W, Borman B, Ellison-Loschmann L, et al. The voice of experience: Results from cancer control New Zealand's first national cancer care survey. N Z Med J. 2010;123(1325):10-9.

68. Paul C, Carey M, Anderson A, Mackenzie L, Sanson-Fisher R, Courtney R, et al. Cancer patients' concerns regarding access to cancer care: perceived impact of waiting times along the diagnosis and treatment journey. Eur J Cancer Care (Engl). 2012;21(3):321-9.

69. Pigott C, Pollard A, Thomson K, Aranda S. Unmet needs in cancer patients: development of a supportive needs screening tool (SNST). Support Care Cancer. 2009;17(1):33-45.

70. Richard M, Parmar M, Calestagne P, McVey L. Seeking patient feedback: an important dimension of quality in cancer care. J Nurs Care Qual. 2010;25(4):344-51.

71. Siekkinen M, Laiho R, Ruotsalainen E, Katajisto J, Pyrhonen S, Leino-Kilpi H. Quality of care experienced by Finnish cancer patients during radiotherapy. Eur J Cancer Care (Engl). 2008;17(4):387-93.

72. Taylor EJ. Prevalence and associated factors of spiritual needs among patients with cancer and family caregivers. Oncol Nurs Forum. 2006:33(4):729-35

73. Treharne G, Lyons A, Kitas G. Medication adherence in rheumatoid arthritis: effects of psychosocial factors. Psychol Health Med. 2004;9(3):337-49.

74. Vikum E, Krokstad S, Westin S. Socioeconomic inequalities in health care utilisation in Norway: The population-based HUNT3 survey. Int J Equity Health. 2012;11(1):48

75. Vyas A, Sambamoorthi U. Multimorbidity and depression treatment. Gen Hosp Psychiatry. 2011;33(3):238-45.

76. Weaver K, Danhauer S, Tooze J, Blackstock A, Spangler J, Thomas L, et al. Smoking cessation counseling beliefs and behaviors of outpatient oncology providers. Oncologist. 2012;17(3):455-62.

77. Weingart S, Price J, Duncombe D, Connor M, Sommer K, Conley K, et al. Patient-reported safety and quality of care in outpatient oncology. Jt Comm J Qual Patient Saf. 2007;33(2):83-94.

78. Yates P, Aranda S, Edwards H, Nash R, Skerman H, McCarthy A. Family caregivers' experiences and involvement with cancer pain management. J Palliat Care. 2004;20(4):287-96. 
79. Arraras J, Illarramendi J, Viudez A, Ibanez B, Lecumberri M, de la Cruz S, et al. Determinants of patient satisfaction with care in a Spanish oncology Day Hospital and its relationship with quality of life. Psychooncology. 2013;22(11):2454-61

80. Husain A, Barbera L, Howell D, Moineddin R, Bezjak A, Sussman J. Advanced lung cancer patients' experience with continuity of care and supportive care needs. Support Care Cancer. 2013;21(5):1351-8.

81. Fitch M, McAndrew A, Harth T. Measuring trends in performance across time: Providing information to cancer patients. Can Oncol Nurs J. 2013;23(4):247-53.

82. Curcio K, Lambe C, Schneider S, Khan K. Evaluation of a cancer survivorship protocol: transitioning patients to survivors. Clin J Oncol Nurs. 2012;16(4):400-6.

83. Hadley J. Insurance coverage medical care use and short-term health changes following an unintentional injury or the onset of a chronic condition. [Erratum appears in JAMA. 2007 Apr 25;297(16):1774]. JAMA. 2007;297(10):1073-84.

84. Jacobsen P, Shibata D, Siegel E, Lee J, Fulp W, Alemany C, et al. Evaluating the quality of psychosocial care in outpatient medical oncology settings using performance indicators. Psychooncology. 2011;20(11):1221-7.

85. Kalauokalani D, Franks P, Oliver J, Meyers F, Kravitz R. Can patient coaching reduce racial/ethnic disparities in cancer pain control? Secondary analysis of a randomized controlled trial. Pain Med. 2007;8(1):17-24.

86. Kennedy Sheldon L, Hilaire D, Berry D. Provider verbal responses to patient distress cues during ambulatory oncology visits. Oncol Nurs Forum. 2011;38(3):369-75.

87. Klosky J, Cash D, Buscemi J, Lensing S, Garces-Webb D, Zhao W, et al. Factors influencing long-term follow-up clinic attendance among survivors of childhood cancer. J Cancer Surviv. 2008;2(4):225-32.

88. McBride M, Lorenzi M, Page J, Broemeling A, Spinelli J, Goddard K, et al. Patterns of physician follow-up among young cancer survivors: report of the Childhood Adolescent and Young Adult Cancer Survivors (CAYACS) research program. Can Fam Physician. 2011;57(12):482-90.

89. Nguyen T, Bosset J, Monnier A, Fournier J, Perrin V, Baumann C, et al. Determinants of patient satisfaction in ambulatory oncology: a cross sectional study based on the OUT-PATSAT35 questionnaire. BMC Cancer. 2011;11:526.

90. Rask M, Jensen M, Andersen J, Zachariae R. Effects of an intervention aimed at improving nurse-patient communication in an oncology outpatient clinic. Cancer Nurs. 2009;32(1):1-11.

91. Rodriguez K, Bayliss N, Alexander S, Jeffreys A, Olsen M, Pollak K, et al. Effect of patient and patient-oncologist relationship characteristics on communication about health-related quality of life. Psychooncology. 2011;20(9):935-42.

92. Rose J, OToole E, Einstadter D, Love T, Shenko C, Dawson N. Patient age well-being perspectives and care practices in the early treatment phase for late-stage cancer. J Gerontol A Biol Sci Med Sci. 2008;63(9):960-8.

93. Sharpe M, Strong V, Allen K, Rush R, Postma K, Tulloh A, et al. Major depression in outpatients attending a regional cancer centre: screening and unmet treatment needs. Br J Cancer. 2004;90(2):314-20.

94. Taylor S, Harley C, Campbell L, Bingham L, Podmore E, Newsham A, et al. Discussion of emotional and social impact of cancer during outpatient oncology consultations. Psychooncology. 2011;20(3):242-51.

95. Thewes B, Butow P, Stuart-Harris R, Group GSAHSSC. Does routine psychological screening of newly diagnosed rural cancer patients lead to better patient outcomes? Results of a pilot study. Aust J Rural Health. 2009;17(6):298-304.

96. Yoon T, Lee S, Kim C, Kim S, Jeong B, Park H. Inequalities in medical care utilization by South Korean cancer patients according to income: a retrospective cohort study. Int J Health Serv. 2011;41(1):51-66.

97. Horvitz-Lennon M, Zhou D, Normand S, Alegria M, Thompson W. Racial and ethnic service use disparities among homeless adults with severe mental illnesses receiving ACT. Psychiatr Serv. 2011;62(6):598-604.

98. Lesser I, Leuchter A, Trivedi M, Davis L, Wisniewski S, Balasubramani G, et al. Insured and non-insured depressed outpatients: how do they compare? Ann Clin Psychiatry. 2007;19(2):73-82.

99. Song D, Sands R, Wong Y-LI. Utilization of mental health services by low-income pregnant and postpartum women on medical assistance. Women Health. 2004;39(1):1-24

100. Tate SR, Mrnak-Meyer J, Shriver CL, Atkinson JH, Robinson SK, Brown SA. Predictors of treatment retention for substance-dependent adults with co-occurring depression. Am J Addict. 2011;20(4):357-65.
101. LeMaster J, Kruse R, Lin W, Lindbloom E, Fryer GJ. Health care expenses for people with diabetes mellitus in the United States: does having a usual care provider make a difference? J Health Care Finance. 2006;32(4):76-87.

102. Ma J, Stafford R. Quality of US outpatient care: temporal changes and racial/ethnic disparities. Arch Intern Med. 2005;165(12):1354-61.

103. Pawaskar M, Burch S, Seiber E, Nahata M, laconi A, Balkrishnan R. Medicaid payment mechanisms: Impact on medication adherence and health care service utilization in type 2 diabetes enrollees. Popul Health Manag. 2010;13(4):209-18.

104. Donabedian A. Aspects of medical care administration: specifying requirements for health care. Harvard University Press; 1973.

105. Aday LA, Andersen R. A framework for the study of access to medical care. Health Serv Res. 1974;9(3):208.

106. Barnett-Page $E$, Thomas J. Methods for the synthesis of qualitative research: a critical review. BMC Med Res Methodol. 2009;9(1):59.

107. Penchansky R. The concept of access: a definition. National Health Planning Information Center; 1977.

\section{Submit your next manuscript to BioMed Central and take full advantage of:}

- Convenient online submission

- Thorough peer review

- No space constraints or color figure charges

- Immediate publication on acceptance

- Inclusion in PubMed, CAS, Scopus and Google Scholar

- Research which is freely available for redistribution 